\title{
WORK SCHEDULING PROGRAM DESIGN FOR LECTURE ATTENDANCE CONTROL AND LECTURER WORKLOAD CALCULATION WITH FINGERPRINT AND RFID IDENTIFICATION DEVICE
}

\author{
M. A. Ade SAPutra ${ }^{1 *}$, Amrifan SAladin Mohruni ${ }^{1}$ ANd IrSyadi Yani ${ }^{1}$ \\ ${ }^{l}$ Dept. of Mechanical Engineering, Faculty of Engineering, Universitas Sriwijaya, Palembang, South \\ Sumatera, Indonesia \\ *Corresponding author: m.a.adesaputra@ft.unsri.ac.id
}

(Received: 21 May 2021; Accepted: 1 October 2021; Published on-line: 1 November 2021)

\begin{abstract}
The essential factor in achieving a good learning process is discipline in the lecture process. Students and lecturers are encouraged to be disciplined and active participants in the lecture process, allowing the Lecturer's principal duty of transforming and disseminating science and technology to become more concentrated. Furthermore, to eliminate overlapping lecture schedules, lecture hours, and lecture venues that do not meet needs, it is easier for stakeholders to monitor and regulate lecturers' and students' lecture attendance so that quick and accurate decision-making can be done. To establish discipline in school utilizing biometric identification technology (fingerprints) and Radio Frequency Identification (RFID) technology, developing application software to make it easier to manage work schedules is required. The Work Scheduling program is an online application built with the PHP programming language, MySQL database, and fingerprint and RFID identification support devices that are expected to be effective and efficient tools in the process of scheduling lectures and recording lecture attendance of students and lecturers, making it easier to publish lecture schedules.
\end{abstract}

KEYWORDS: Work Scheduling, PHP, MySQL, Fingerprint and RFID, Lecturer Work Load

\section{INTRODUCTION}

The scheduling problem emerges because of the restrictions of time, energy work, the number of machines/tools, the nature, and the situation of employment. In the industrial sector, scheduling is required to reduce the excessive pile of work and the density of processing time. For example, the schedule can anticipate the number of products that the company will make within the stipulated time frame by determining how long it takes to operate in the manufacturing process. Thus, scheduling is to make the most efficient use of the available power to achieve the production goal.

To get optimal results, all production tasks must be meticulously planned. Rescheduling production aimed to find a work assignment that was efficient at each workstation. Therefore, there is no building of jobs that can minimize idle or waiting time for the following work process due to rescheduling.

Scheduling is the process of determining when operational activity will take place. Scheduling entails actions such as allocating resources, such as facilities, equipment, or staff. The final step before the start of operations is to make a schedule decision. Work scheduling is done to make effective use of source power so that the user's or users' goals are satisfied. 
Researchers undertake the development of technology similar to apply the system automated management that facilitates student surveillance and reduces the burden of staff administration the school in the development of the study. The research system of administration of the school is using Rfid technology (Radio Frequency Identification). Data people, classroom/laboratory, attendance management, alert submission, notification, and reporting can be automatically made using automated management [1]. The previous study used the system biometric fingerprint in constructing applications based on the web-device software-oriented object dubbed OBCAMS (an online biometrics-based class attendance management system) to process and manage the class's presence [2]. Furthermore, the development of an attendance registration system (attendance register system) based on application-based web technologies such as PHP, MySQL, and Apache to serve the recording and reporting of student presence [3]. The system's development is inspired by the fact that it is one of the most critical indicators of academic accomplishment in a high-performing educational institution.

Popular systems for recording attendance include RFID (radio frequency identifier) and biometrics [4]. The use of RFID and biometrics (face-detection) technologies by MIS (Management Information System) students will improve the management of student absenteeism. Using RFID to record attendance every day, retaining the data, and analyzing the data in real-time have advantages such as saving paper and ink. This technique is more efficient than manual attendance, which is time-consuming and dangerous [5]. In addition, an SMS service will be provided by the system to offer information regarding student attendance.

Scheduling and recording attendance in the lectures is the way of doing the design of the system by using the application-based web such as ASP.NET and IIS servers to meet the recording and reporting of the presence of students, the Lecturer can easily access the system through the web, and reports can be generated in real-time. Thus, this study utilizes a system of RFID to record the number of students who attend it. The student ID card is embedded with an RFID tag that can be read by a reader [6].

To reach an objective, employees must be identified and authenticated [7]. Because of the items that others can exploit, identifying and validating an employee's identification with a name, ID number, and a hand sign is insufficient. Fingerprint fingers can be used to identify each individual because each person's fingerprints are unique. Fingerprint fingers will promote employee attendance by enhancing safety, productivity, and skills, which will boost the organization's success, thanks to employee identification and authentication methods that use technology identification. People management is a demanding issue for most prominent firms, and attendance is crucial in people management [8]. To reduce man's error in conducting calculations, a system that is efficient in electronic with a system that introduces fingerprint fingers was required. The system proposed for controlling the problem of tardiness and absenteeism in a school.

The lectures also necessitate a well-planned timetable. Some factors and conditions determine whether or not the college is successful or whether or not other factors impact the college. Discipline in the lecture hall is just as crucial for a successful learning experience. Students, including lecturers, were encouraged to be disciplined and active participants in the lecture process, allowing the role of guiding lecturers to convert, develop, and spread scientific information and technology to be more concentrated. Furthermore, as an educator, researcher, and servant to the people known as Tridarma university higher, the Lecturer needs to have a load of work that will be reviewed and reported regularly as a form of accountability of the lecturers' performance the stakeholder interests. 
The lecture scheduling process must be done in a reasonable and planned manner to avoid overlapping course schedules. In addition, stakeholder interests will efficiently monitor and regulate lecture attendance, both professors and students, if the scheduling process has been organized cleanly and appropriately, allowing for quick and precise decision-making.

College students will need to design a program that includes program management and control of presence-based online programs and the use of technology identification as biometric (fingerprint fingers, palms of hands, retina eyes, face, voice, and others) methods using RFID and device identification. In addition, to achieve the discipline in the course, you will need a system that provides commands that a computer can handle to make it easier to control the work schedule.

Manual methods are particularly vulnerable to data tampering. Furthermore, if done manually, the accuracy of data collection and documenting attendance during lectures is a considerable challenge. An application program covering all of these objectives is needed to improve discipline and accuracy, simplify scheduling lectures, monitor, manage attendance, and process lecturer workload calculations. As a result, this research offered a design program application to improve the discipline and efficacy of lecturing scheduling (the course process), particularly in monitoring and controlling the presence of students and lecturers.

\section{MATERIALS AND METHOD}

Figure 1 shows the entire study process.

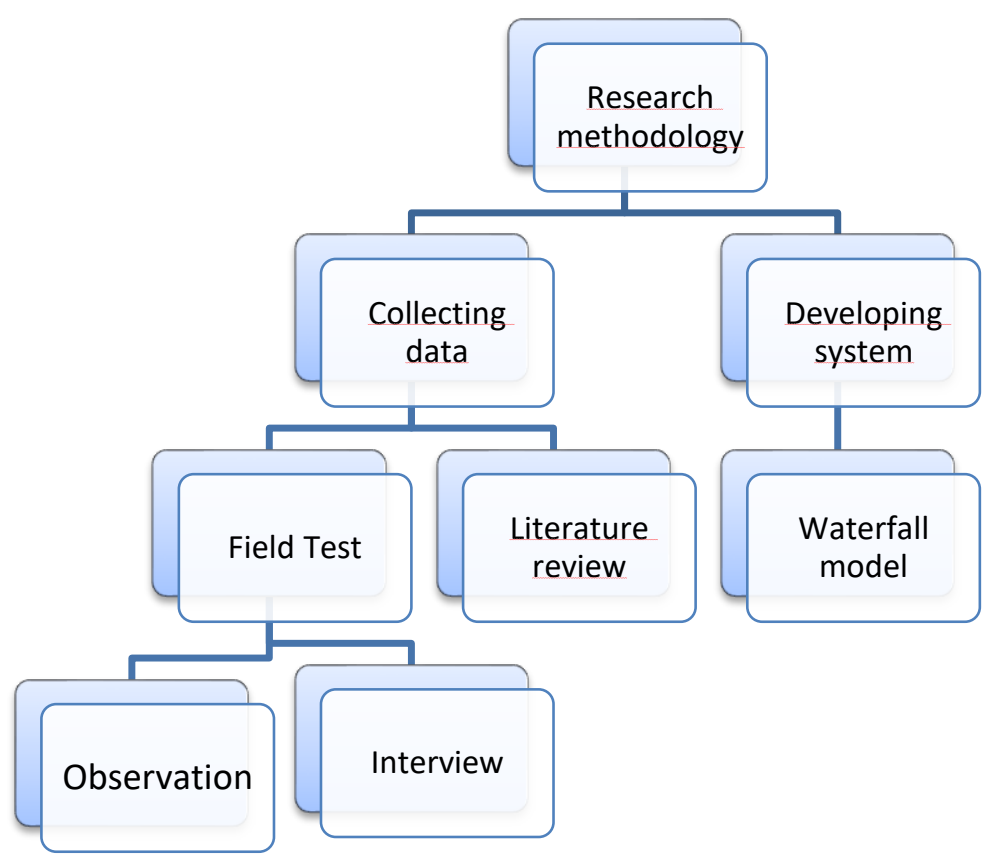

Fig. 1. Research methodology

\subsection{Data Collection}

\subsubsection{Field test}

\section{Observation}

The research item (Universitas Sriwijaya's Magister Program in Mechanical Engineering Department), the mechanism for documenting student and lecturer attendance, and the performance assessment of the Lecturer's workload were all monitored. 


\section{Interview}

Students, Lecturers, and the Deputy Dean were interviewed in three groups. The interviews with students and lecturers were about the attendance recording system. The Deputy Dean (Field of General and Finance) is in charge of calculating the workload performance of Lecturers.

\subsubsection{Literature review}

Studying supporting books and associated research publications, including literature on writing and topics that support building applications, and learning from other data sources such as the internet and programming reference $\mathrm{CDs}$, are used to acquire data.

\subsection{System Development}

After data was collected, it was continued using the waterfall for system development.

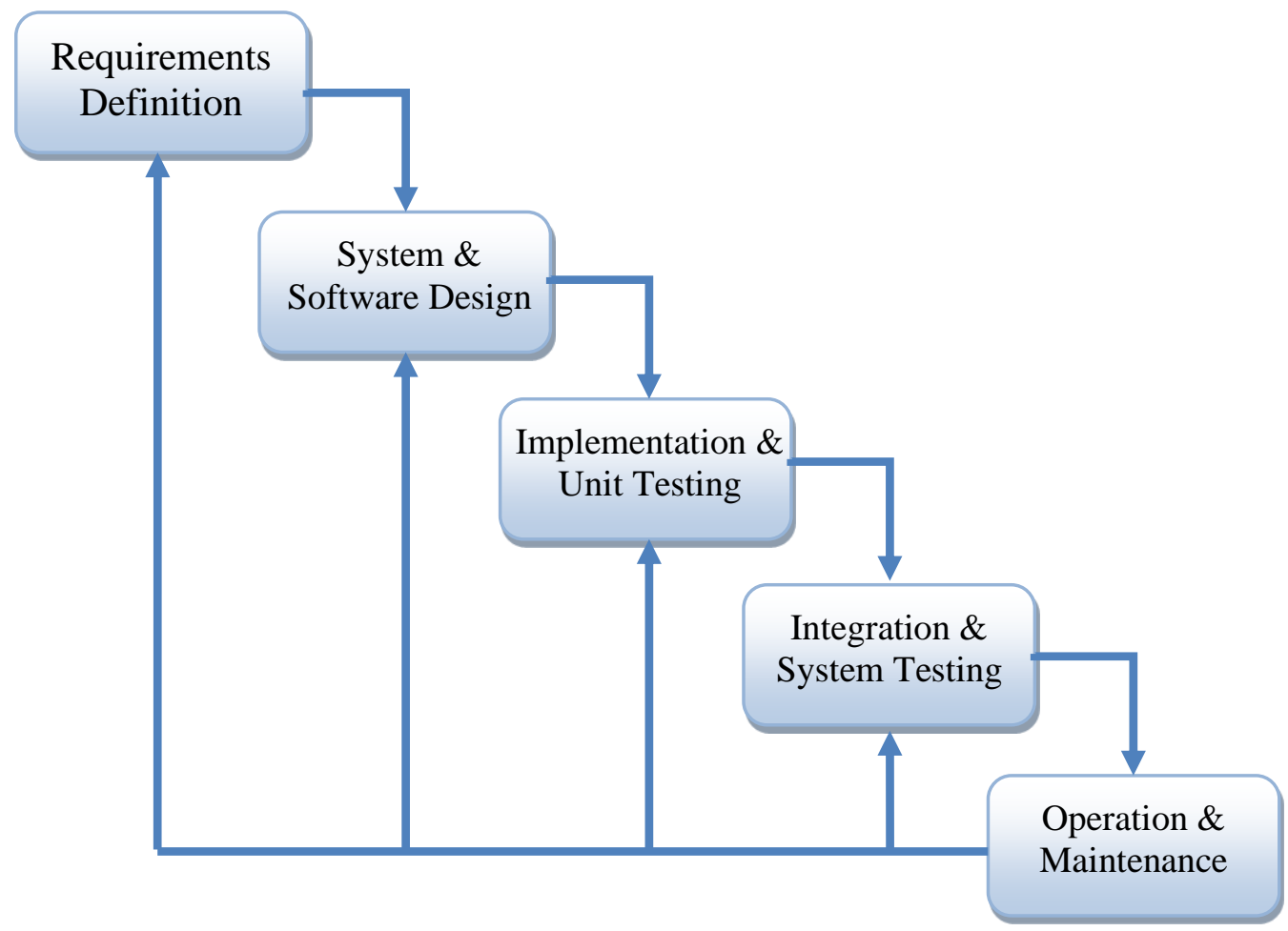

Fig. 2. Waterfall system development model [9]

1. Definition of requirements needed to design applications, such as user data, class schedules, and supporting tools needed

2. Design systems and software using a model of data flow diagrams (DFD) to show how the existing data in the application are processed and use Flow Chart to define in detail 1 steps for software design to be built.

3. Implementation and unit testing: the stages of making programs based on designs that have been made previously using the PHP programming language and MySQL database.

4. Integration and system testing: unites program units into a single unit and is tested as an application system that can be implemented, such as the data input and report processes. 
5. Operation and maintenance: using and adjusting the program that has been completed.

\section{RESULTS AND DISCUSSION}

\subsection{System Overview}

In the development of this system, it integrates interconnected hardware and software components shown in Fig 3.

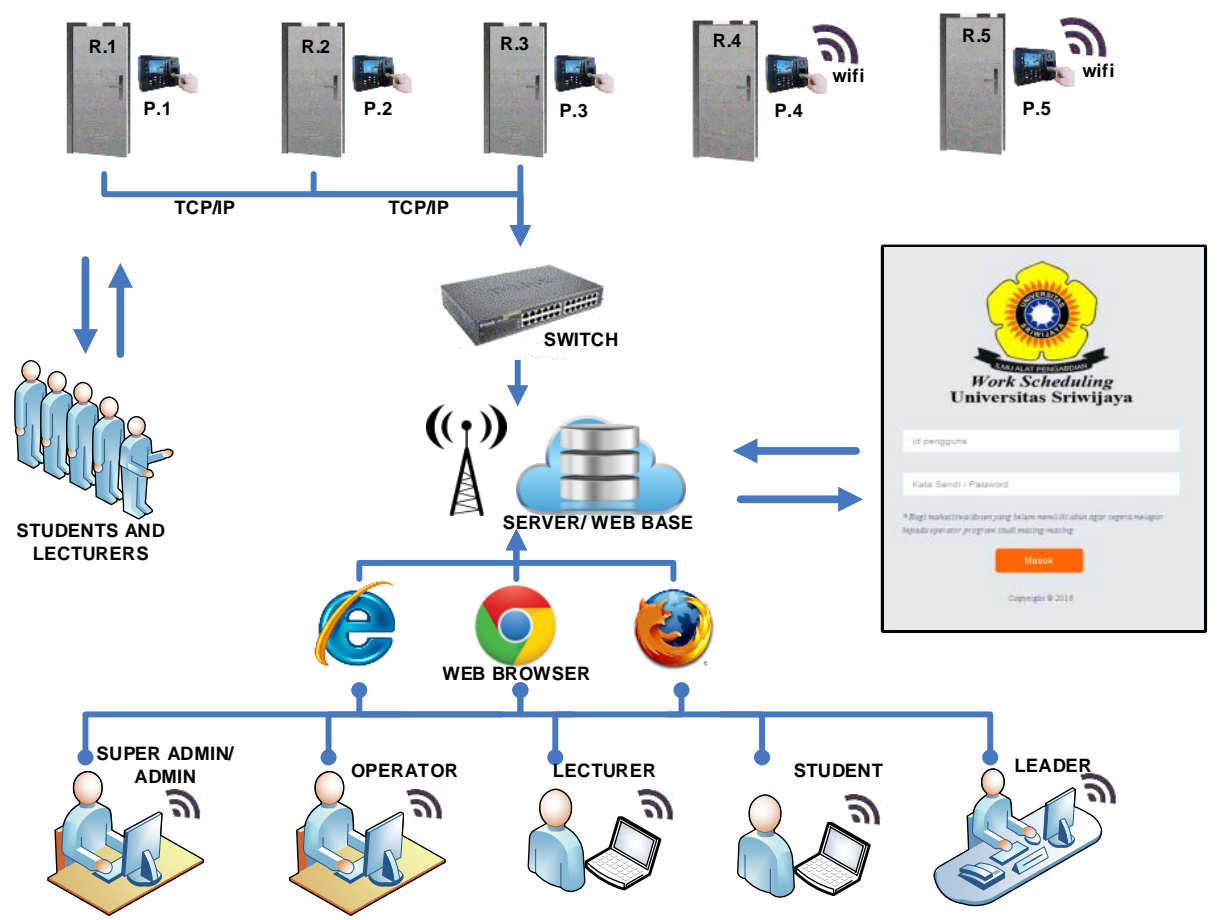

Fig. 3. System overview

In each classroom, hardware fingerprint identification and RFID (Solution S401) are utilized to connect online to the work scheduling program (see Fig. 3). Students and lecturers with a lecture schedule can scan their identification using fingerprints or RFID cards to track attendance at each lecture. The data from the identification device will be recorded and sent straight to the online job scheduling program. Thus, every user has access to the attendance records that have been created. 


\subsection{Implementation and Testing}

\subsubsection{Log in Page and Main Menu}

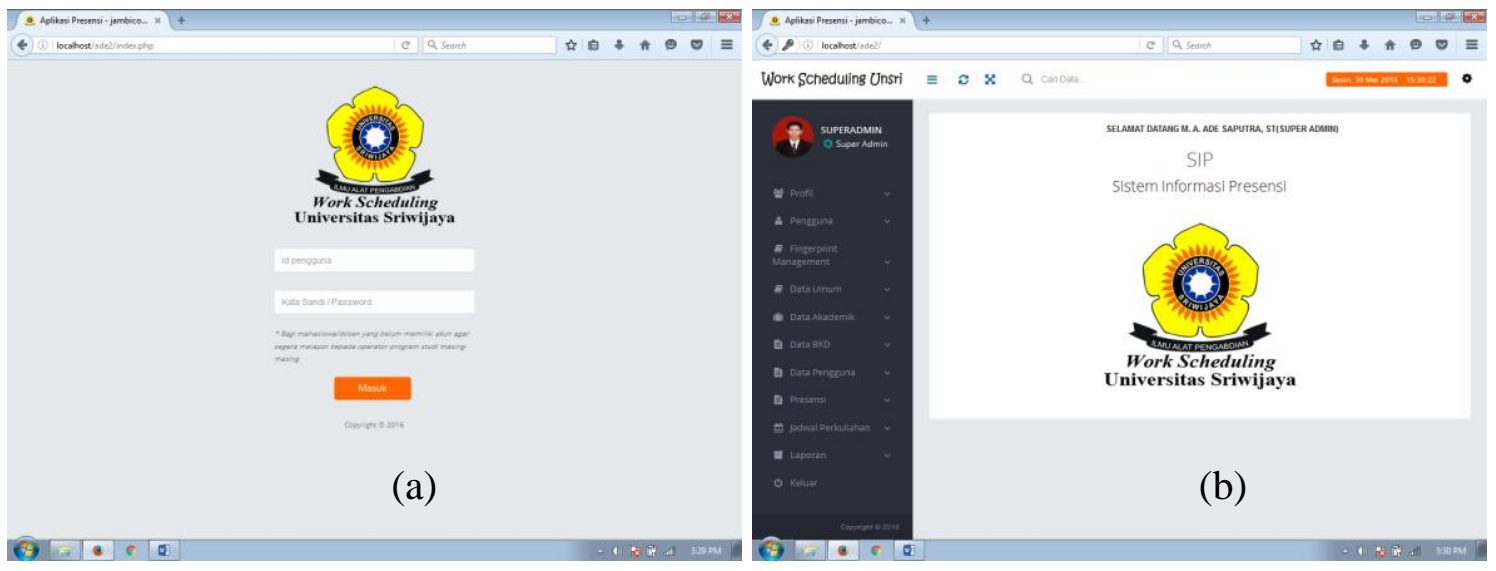

Fig. 4. (a) Log in Page, (b) Main Menu Page

The initial interaction page for each user, super Admin, Admin, operator, leader, Lecturer, and student who will utilize the program is Fig. 4.a (on the log-in page). To be able to utilize this software, each user must first log in. Only registered users are allowed to access this program, which is why this log-in page exists. Each user has a username/user ID and a password that has been saved in the system.

The main menu page (Fig. 4.b) is the first page the user sees after logging in to the system. The main menu page displays profile menus, user data menus, lecture schedule menus, report menus, and other menu options. The menu items that show will be different depending on the user's skill level.

\subsubsection{User Profile Page}

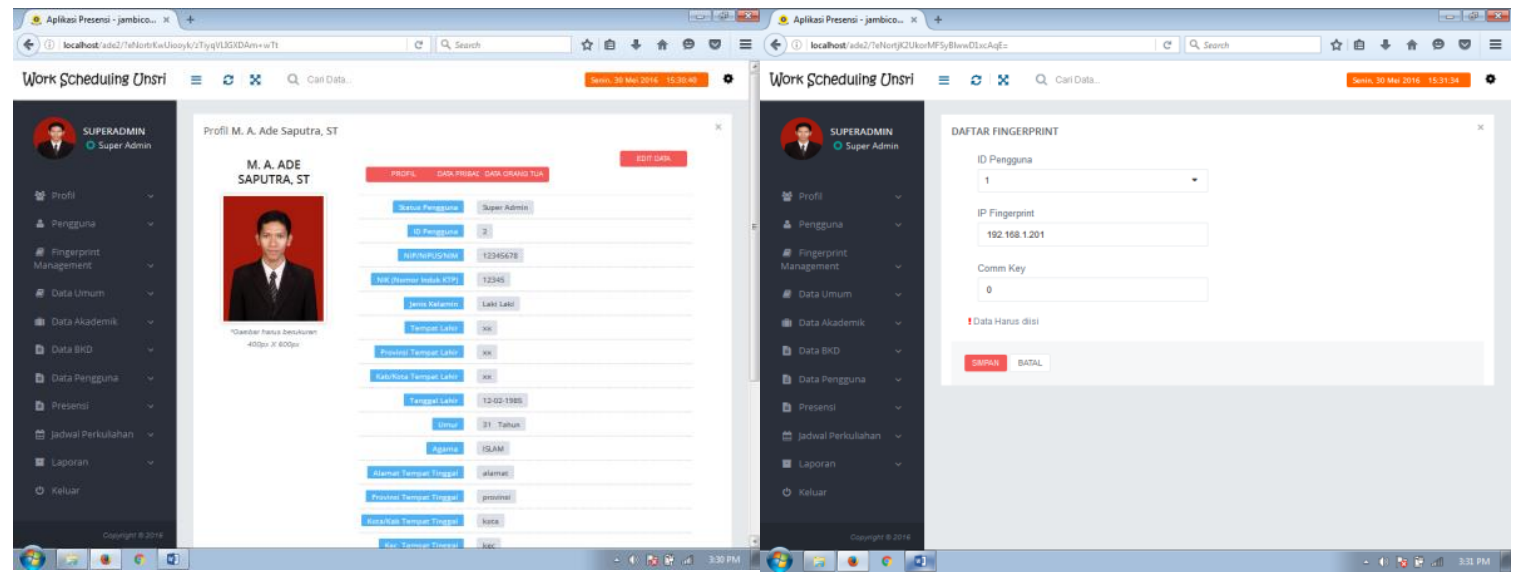

(a)

(b)

Fig. 5. (a) User profile page, (b) Add user page

Fig. 5.a (user profile page) is a page that shows all of the information for each user, including the user's information, user identity number, address, and other information. Aside from that, the user's details and academic history are displayed on the profile page.

User ID, NIP/NIM, user name, username, password, user status, faculty, and user study program will be displayed on the add user screen (see Fig. 5.b). 
According to the specified access restrictions, this user data add page can only be accessed by Super admin, Admin, and Operator users.

\subsubsection{Fingerprint/RFID Data Page and Machine Settings}

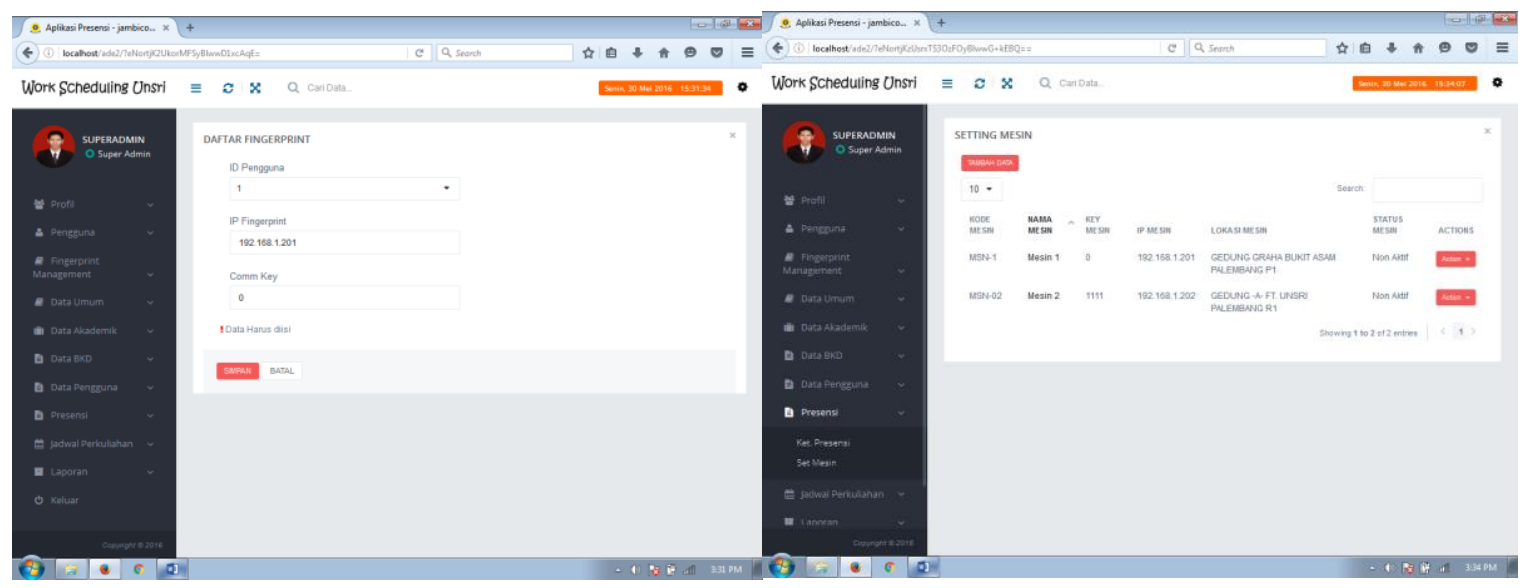

(a)

(b)

Fig. 6. (a) Fingerprint/RFID Data Page, (b) Fingerprint/RFID Setting Page

Super admin users, Admins, and Operators use Fig. 6.a-b (the Fingerprint or RFID data page) to register identification machines in each classroom or erase unused machine data. Users can also set up identification machines to link their gadgets to the app. The machine code, name, IP, location, and status were displayed on the machine settings page.

\subsubsection{Class Schedule Page}

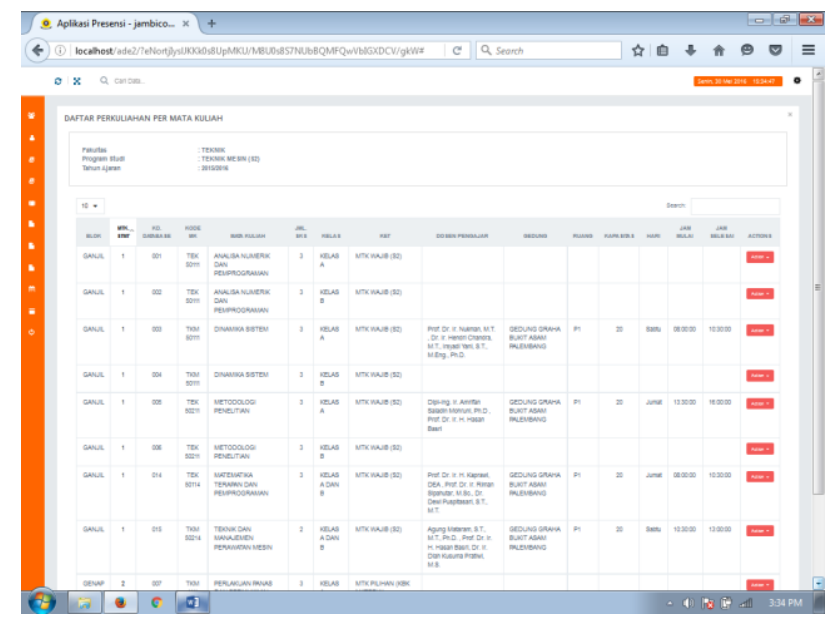

Fig. 7. Class schedule page

The lecture schedule page is a page that displays statistics for each course's lecture schedule based on the study program selected. According to the registered faculty and study program, this lecture schedule page can show on any user (Fig. 7). The lecture schedule page will include information in the form of course blocks, whether odd or even, course code, course name, amount of credits, teaching lecturers, building, room, student capacity, lecture day, and class start to end time. According to the study plan card, student users will select the courses to be taken in the current semester. 


\subsubsection{BKD Report Page and Print Report}

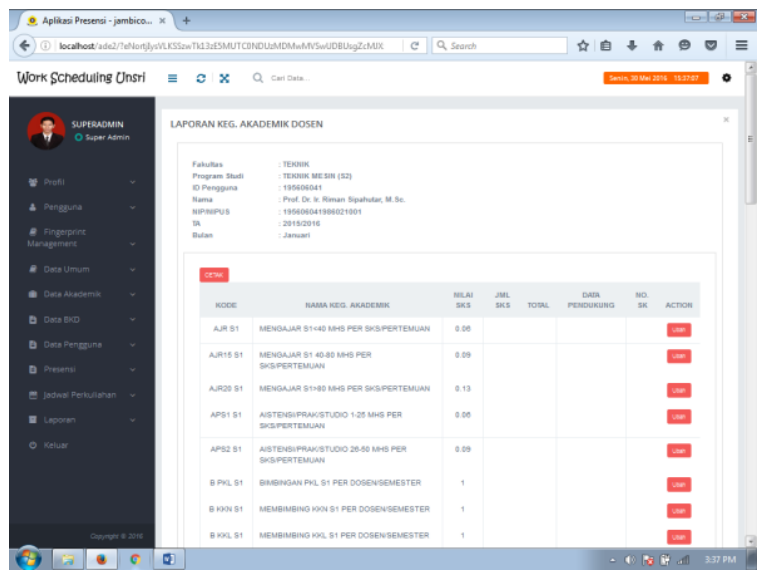

(a)

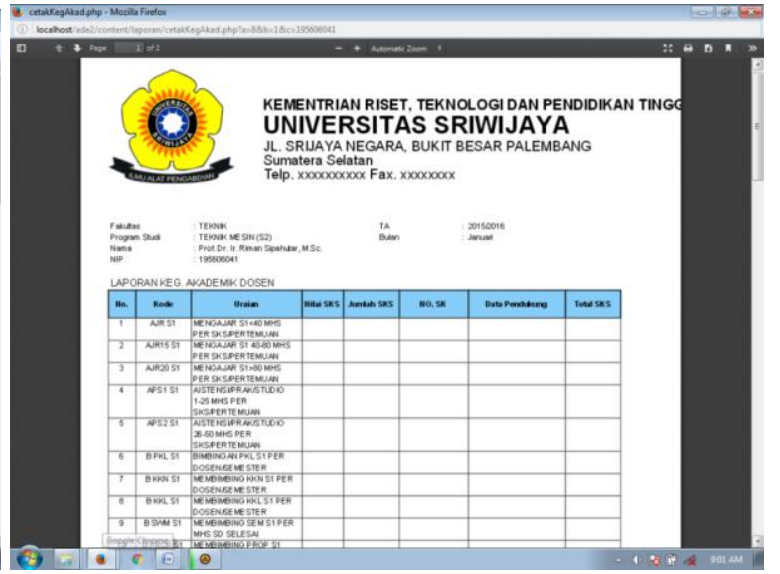

(b)

Fig. 8. (a) Lecturer workload calculation page, (b) Report print page

The lecturer workload calculation page is a portal that displays reports on lecturers' workload in terms of academic and lecturer support activities. Lecturer workload calculation report data is input by super admins, admins, and operators based on the current month and academic year, with supporting proof attached. Lecturers can access and examine workload calculation reports for the current month and academic year based on data entered by operators, and Super administrators, admins, and lecturers can print and save these reports. Figure 8-a shows the lecturer workload calculation report page. Lecturers can print a report on their workload calculation (Fig. 8.b).

\subsubsection{Lecturer/Student Presence Report Page}

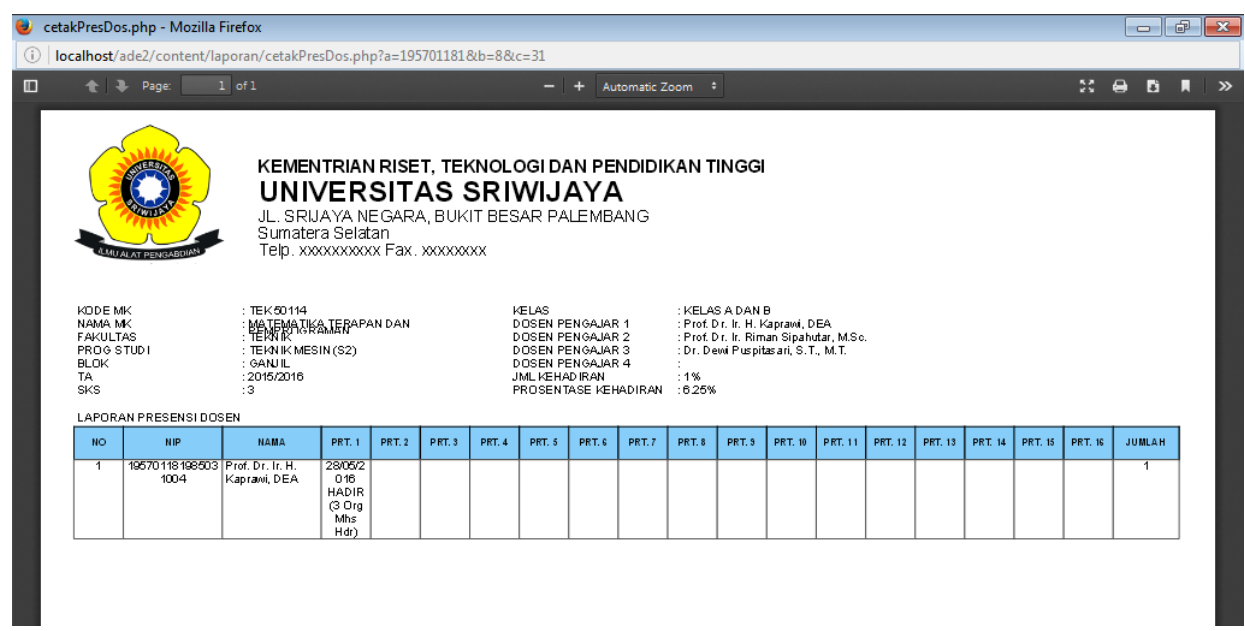

Fig. 9. Attendance report page

The lecture attendance report page for lecturers and students is where they can view completed lecture attendance reports. The course data, names, and identities of lecturers/students, lecture dates and hours, lecture descriptions, and student statistics are all displayed on this attendance report page (Fig. 9). 


\subsection{Support Device}

Attending lectures with the Work Scheduling Program requires supporting devices such as a fingerprint and RFID attendance machine that seeks to detect the user's fingerprint or RFID card identifying number (Fig. 10). The following are the specifications for the identifying support device utilized in this work scheduling program.

\begin{tabular}{l|l}
\hline Device Name & X401 \\
\hline Serial Number & 6530155300144 \\
\hline Produce Date & $2016-01-04$ 20:11:50 \\
\hline IP Address & 192.168 .1 .201 \\
\hline User capacity & $50000 / 29$ \\
\hline Transaction capacity & $500000 / 38$ \\
\hline Finger capacity & $50000 / 7$ \\
\hline Lock & Enable \\
\hline RF Card & Enable \\
\hline Short Message & Enable \\
Management & Enable \\
\hline Usb Disk & Disable \\
\hline Usb Client & Disable \\
\hline Remote Identification & \\
Server &
\end{tabular}

Fig. 10. Attendance machine support device specifications

Solution items with the X401 product series with a capacity of 50,000 fingerprints, 50,000 cards, and 500,000 transactions provide supporting equipment in the form of fingerprint recognition and RFID attendance machines (Fig. 11.a-b). TCP/IP (RJ45), RS232/485, USB Cable, and USB Disk are examples of data connection methods. 1 second to respond. A 1.3 MegaPixel digital camera, RFID Proximity Reader, USB Flash Disk, Internal Lithium Battery, Fingerprint Cover, web server, and other functions.

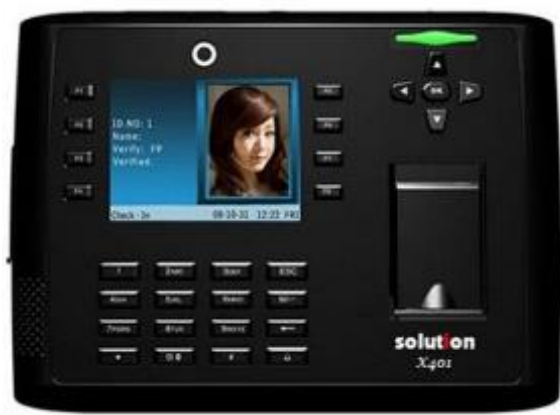

(a)

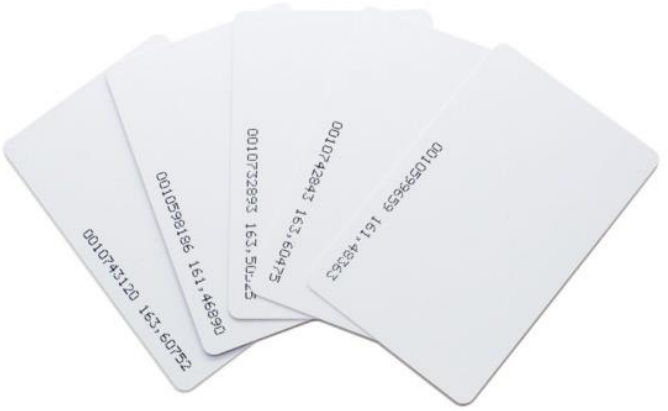

(b)

Fig. 11. (a) Solution X401, (b) RFID card

\subsection{Machine Connection}

We are adjusting the IP address of the machine and computer by distinguishing the last 3 (three) digits of the IP Address number in the process of connecting the Work Scheduling application with supporting devices in the form of a fingerprint attendance machine and RFID using TCP/IP (RJ45) cable communication. The image below shows how IP Address settings are displayed on computers and supported devices (Fig. 12.a-b). 


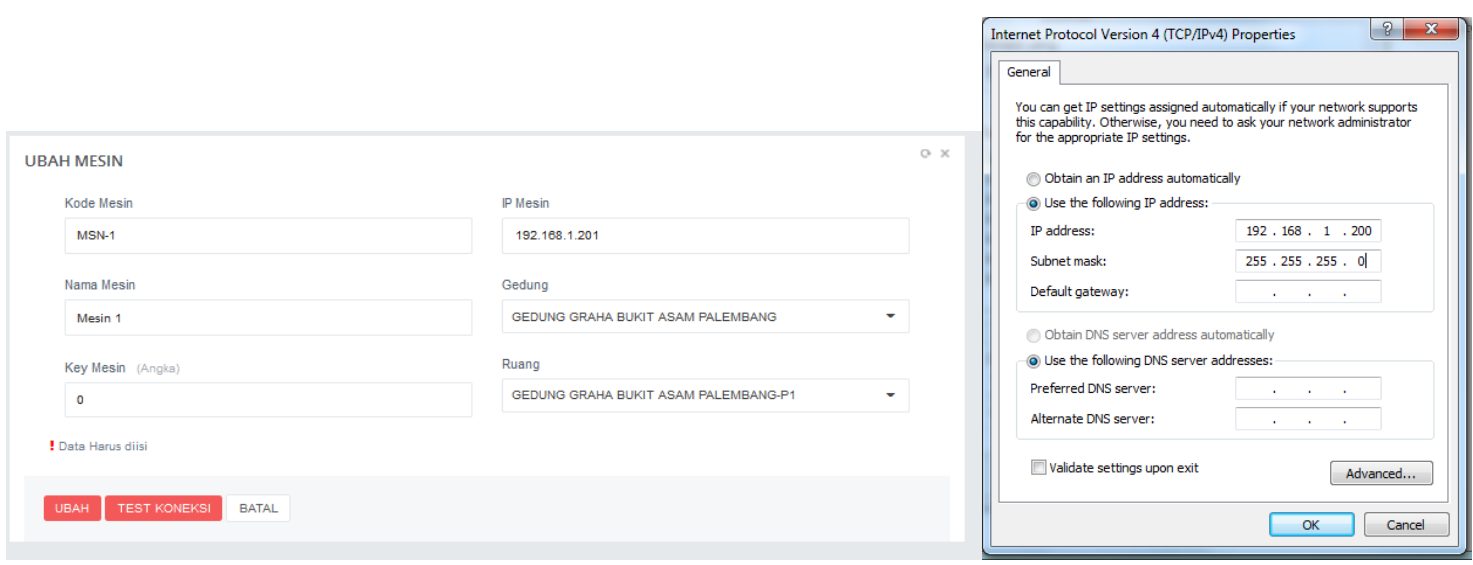

(a)

(b)

Fig. 12. (a) Setting the IP address connection on the work scheduling application, (b) Setting the IP address connection and the computer

\section{CONCLUSION}

After testing the functionality of the Work Scheduling Program based on Fingerprint and RFID for monitoring systems, lecture control, and calculating the workload of lecturers, the following conclusion can be reached:

- This Work Scheduling application program can help simplify publishing and changing lecture schedules, as well as the calculation of lecturers' workloads, according to the needs that exist in the Magister Program in Mechanical Engineering Department - Universitas Sriwijaya.

\section{ACKNOWLEDGEMENT}

Thanks to Universitas Sriwijaya for facilitating this research.

\section{REFERENCES}

[1] S. Akpınar and H. Kaptan, "Computer-aided school administration system using RFID technology," Procedia - Soc. Behav. Sci., vol. 2, no. 2, pp. 4392-4397, 2010.

[2] E. Adetiba, O. Iortim, A. Olajide, and R. Awoseyin, "OBCAMS: An Online Biometrics-based Class Attendance Management System," IEEE African J. Comput. ICT, vol. 6, pp. 25-38, 2013.

[3] M. Othman, S. N. Ismail, and M. Raus, "The development of the web-based Attendance Register System (ARS) for the higher academic institution: From feasibility study to the design phase," 2009.

[4] T. Nawaz and S. Pervaiz, "Development of Academic Attendance Monitoring System Using Fingerprint Identification," 2009.

[5] P. Nikam, B. Ahuja, and M. Deshmukh, "Combined RFID-Biometric based MIS for student information," 2013.

[6] A. A. Mohammed and J. Kameswari, "Web-server based student attendance system using RFID technology," Int. J. Eng. Trends Technol., vol. 4, no. 5, p. 4, 2013.

[7] M. D. Chiwa, "Secured employee attendance management system using fingerprint," IOSR J. Comput. Eng., vol. 16, pp. 32-37, 2014.

[8] K. S. Adewole, S. O. Abdulsalam, R. S. Babatunde, T. M. Shittu, and M. O. Oloyede, "Development of fingerprint biometric attendance system for non-academic staff in a tertiary institution," Development, vol. 5, no. 2, pp. 62-70, 2014.

[9] R. S. Pressman, Software Engineering: A Practitioner's Approach. Seventh Edition. New York: McGraw-Hill, 2010. 
